\title{
Application of cook balloon during aorta replacement in a pregnant Marfan- syndrome patient: a case report
}

\author{
Lu Zhang ${ }^{1}$, Bin Yan ${ }^{1}$, Xue Cui ${ }^{1}$, Jinghong Liu $^{2}$ and Fangxin Shi ${ }^{1 *}$
}

\begin{abstract}
Background: Aortic dissection is a rare and emergent condition. Aortic dissection during pregnancy is not much known but it is quite lethal to both mother and infant. Earlier reports published show that clinicians conducted hysterectomies during cesarean section to avoid anticoagulant-induced uterine bleeding during the following aortic surgery.
\end{abstract}

Case presentation: A woman (38, gravida 1, para 0) in the 37th gestational week suffered an acute, severe, sharp pain in the chest and back. She was diagnosed with Standford type A aortic dissection and suspected with Marfan syndrome. An emergency cesarean section was performed immediately to deliver the baby. Since the patient was on anticoagulants during aortic replacement, so Cook balloon was inserted into the uterus to prevent postpartum hemorrhage. This helped to maintain the uterus intact. Family genetic testing showed that the patient was a carrier of FBN1 mutation which was inherited from the patient's mother, and the newborn also carried the mutation. Hence the patient was concluded to be positive for Marfan syndrome.

Conclusion: It is important that clinicians should pay attention to the possibility of aortic dissection in a pregnant woman with chest, abdominal or back pain. In this case study, we employed Cook balloon during cesarean section to avoid anticoagulant-induced uterine bleeding during the following aortic surgery.

Keywords: Aortic dissection, Marfan syndrome, Pregnancy, Cook balloon

\section{Background}

Aortic dissection is a relatively rare condition, with a general occurrence rate of 2.9/100,000/yr [1]. It is, therefore, crucial to diagnose the condition correctly and rapidly and to administer immediate and appropriate treatment. Aortic dissection during pregnancy is even rarer than in normal patients. Pregnancy seems to increase the risk of aortic dissection in women with Marfan syndrome on account of blood-vessel alterations, particularly in the third trimester [2]. Through this study, we report successful treatment of Standford type A aortic dissection in a pregnant Marfan-syndrome patient.

\footnotetext{
*Correspondence: shifangxin1122@163.com

'Department of Obstetrics and Gynecology, First Affiliated Hospital of Dalian Medical University, Dalian 116011, China

Full list of author information is available at the end of the article
}

\section{Case presentation}

The patient at hand was a woman (38, gravida 1 , para 0 ) in the 37th gestational week. She suffered an acute, severe, sharp pain in the chest and back and was admitted to our hospital in January 2018. She had no history of vascular disease or hypertension and was uncertain of familial history. Her blood pressure measured $107 / 38 \mathrm{mmHg}$. A transthoracic two-dimensional echocardiography revealed a severely dilated aortic root $(\varnothing 58 \mathrm{~mm})$ and severe aortic valve insufficiency. Aortic computed tomography angiography (CTA) led to the diagnosis of the Standford type A aortic dissection (Fig. 1). The patient was slender with a height of $173 \mathrm{~cm}$ and featured spider-like fingers and toes (having "wrist sign"). We suspected her having Marfan syndrome. The fetal ultrasound was inconspicuous, with a normally developed fetus and $3 \mathrm{~h}$ 


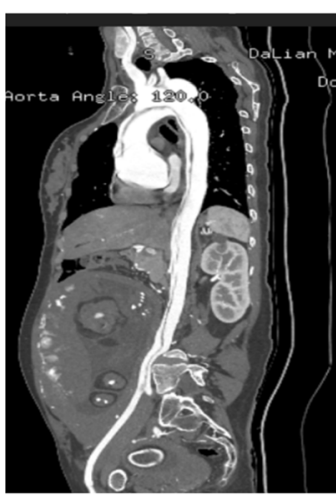

A

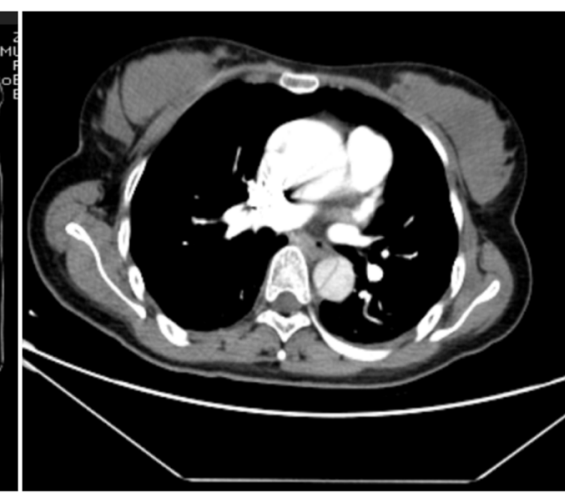

$B$

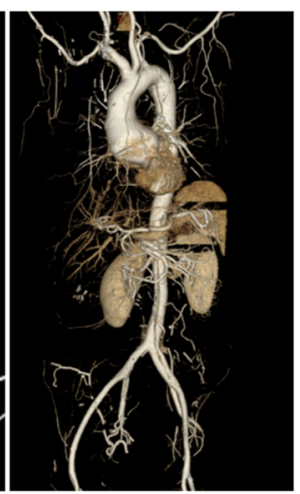

C

Fig. 1 Aortic computed tomography angiograms. a Aortic dissection from ascending aorta to abdominal aorta and the fetus in the uterine cavity. b Acute aortic dissection with a false lumen. c 3-D reconstruction of the aorta, showing dilated aortic sinuses of Valsalva

post-admission, the patient underwent an emergency cesarean section with full anesthesia. Blood pressure was carefully monitored during the surgery. A 2950-g infant was born (Apgar score: 9 at $1 \mathrm{~min}, 10$ at $5 \mathrm{~min}$ ). After the baby was born, the patient was administered with $20 \mathrm{u}$ oxytocin intravenously. To prevent postpartum bleeding during aorta replacement, potentially caused by the anticoagulants in the extracorporeal circulation, we inserted Cook balloon containing $400 \mathrm{ml}$ of normal saline into the uterus during the cesarean section. The aortic root, ascending aorta and aortic arch was replaced under cardiopulmonary bypass and hypothermia $\left(25^{\circ} \mathrm{C}\right)$. Vaginal bleeding during the six-hour surgery was modest $(<150 \mathrm{ml})$. The Cook balloon was removed from the patient $24 \mathrm{~h}$ post-surgery leaving an intact uterus. The patient was released after 20 days. In order to make a definite diagnosis, we did the genetic testing of the patient's family. The patient carried an FBN1 mutation and the site was chr15:48905206. The mutation was NM 000138.4:c. $247+1 G>T$. We also discerned that the patient's $\mathrm{Z}$ score of aortic root diameter was 7.5. The above findings were correlated to the Ghent-2 criteria and we confirmed that she was having Marfan syndrome. Family genetic testing showed that the mutation inherited from the patient's mother, and the newborn also carried the mutation. We explained the result of genetic testing to the patient and the genetic mode of autosomal dominant inheritance. She was advised contraception and restricting activity. Also we made her aware of the impact Marfan syndrome would have on her newborn's health. Both she and her baby need a close follow-up. The patient was followed up by the cardiologist three times after discharge.

\section{Discussion and conclusion}

Marfan syndrome (MFS) is a dominant, autosomal inherited disorder of connective tissue that leads to the damage of cardiovascular, skeletal and ocular systems.
The most serious MFS-induced complication is aortic dissection. The overall risk of a pregnant woman with MFS having an aortic dissection is about 3\% [3] wherein dissection occurs often either in the last trimester of pregnancy or the early postpartum period. A recent study comprising of 12 UK centers, over the past 20 years shows that the rate of aortic dissection in pregnant women with MFS was $1.9 \%$ (one type A and four type B) and there were no deaths. It also reports that preconception counseling rates were low [4]. The patient in our case did not undergo pre-conception counseling. If the patient had been diagnosed with MFS before pregnancy, a comprehensive evaluation would have been conducted to determine whether she can be pregnant. According to the 2018 ESC guidelines, pregnancy should be avoided in Marfan patients with an aortic root diameter $>45 \mathrm{~mm}$ due to the increased risk of dissection [5]. Earlier studies show that aortic dissection during pregnancy is a life-threatening condition with fetal mortality around $20-30 \%$ [6]. Hence, obstetrical specialists are required to show vigilance toward known clinical presentations of MFS, including elongated extremities, wrist and thumb sign, pectus deformity, facial features, scoliosis, and, to facilitate early diagnosis to prevent detrimental outcomes.

To avoid anticoagulant-induced uterine bleeding during aortic surgery, earlier clinicians have conducted hysterectomies as a preventive measure $[7,8]$. In the case we present, $20 \mathrm{u}$ oxytocin was intravenously administered to the patient after the baby was born. We did not choose intrauterine suture-"B-Lynch" because the wound of "BLynch" may bleed during aortic surgery. In order to minimize the wound, we used a Cook balloon to prevent uterine bleeding.

In conclusion, clinicians should pay attention to the possibility of aortic dissection in a pregnant woman with 
chest, abdominal or back pain because correct and rapid diagnoses and immediate treatment are extremely important. Through this case report, we used Cook balloon during cesarean section to avoid anticoagulant-induced uterine bleeding following aortic surgery in a pregnant patient with Marfan syndrome.

\section{Abbreviations}

CTA: Computed tomography angiography; MFS: Marfan syndrome

\section{Acknowledgements}

The authors thank the staff at the Department of Cardiacvascular Surgery in First Affiliated Hospital of Dalian Medical University.

\section{Authors' contributions}

ZL was responsible for writing the manuscript. ZL and CX collected the patient data. The surgery was performed by SFX and YB. LJH was responsible for reading the aortic computed tomography angiography (CTA). All authors read and approved the final manuscript.

\section{Funding}

No financial support was received for this study.

\section{Availability of data and materials}

Not applicable.

\section{Ethics approval and consent to participate}

Not applicable.

\section{Consent for publication}

The patient agreed to publish all of her individual data. Written informed consent for publication of the clinical details and clinical images was obtained from the patient. A copy of the consent form is available for review by the Editor of this journal.

\section{Competing interests}

The authors declare that they have no competing interests.

\section{Author details}

'Department of Obstetrics and Gynecology, First Affiliated Hospital of Dalian Medical University, Dalian 116011, China. ${ }^{2}$ Department of Radiology, First Affiliated Hospital of Dalian Medical University, Dalian, China.

Received: 19 February 2019 Accepted: 10 March 2020

Published online: 18 March 2020

\section{References}

1. Mészáros I, Mórocz J, Szlávi J, et al. Epidemiology and clinicopathology of aortic dissection. Chest. 2000;117(5):1271-8 PubMed PMID:10807810.

2. Immer FF, Bansi AG, Immer-Bansi AS, et al. Aortic dissection in pregnancy: analysis of risk factors and outcome. Ann Thorac Surg. 2003;76:309-14 PubMed PMID:12842575.

3. Smith K, Gros B. Pregnancy-related acute aortic dissection in Marfan syndrome: a review of the literature. Congenit Heart Dis. 2017;12(3):251-60. https://doi.org/10.1111/chd.12465 PMID:28371362.

4. Cauldwell M, Steer PJ, Curtis SL, et al. Maternal and fetal outcomes in pregnancies complicated by Marfan syndrome. Heart. 2019;105(22):1725-31. https://doi.org/10.1136/heartjnl-2019-314817 PMID:31129614.

5. Regitz-Zagrosek V, Roos-Hesselink JW, Bauersachs J, et al. 2018 ESC guidelines for the management of cardiovascular diseases during pregnancy. Eur Heart J. 2018;39(34):3165-241. https://doi.org/10.1093/ eurheartj/ehy340 PMID:30165544.

6. Yates MT, Soppa G, Smelt J, et al. Perioperative management and outcomes of aortic surgery during pregnancy. J Thorac Cardiovasc Surg. 2015;149(2): 607-10. https://doi.org/10.1016/j.jtcvs.2014.10.038 PMID:25524653.

7. Sato A, Ishida M, Ishibashi $\mathrm{K}$, et al. A case of acute aortic dissection in a woman with Marfan syndrome at 29 weeks' gestation. J Obstet Gynaecol. 2014;34(4):358. https://doi.org/10.3109/01443615.2013.872608 PubMed PMID:24476397.
8. Sterner D, Probst C, Mellert F, Schiller W. Surgical treatment and thoracic endovascular aortic repair in type a aortic dissection in a pregnant patient with Marfan syndrome. Ann Vasc Surg. 2014;28(5):1317-0. https://doi.org/10. 1016/j.avsg.2013.10.011 PubMed PMID:24365078.

\section{Publisher's Note}

Springer Nature remains neutral with regard to jurisdictional claims in published maps and institutional affiliations.

\section{Ready to submit your research? Choose BMC and benefit from:}

- fast, convenient online submission

- thorough peer review by experienced researchers in your field

- rapid publication on acceptance

- support for research data, including large and complex data types

- gold Open Access which fosters wider collaboration and increased citations

- maximum visibility for your research: over $100 \mathrm{M}$ website views per year

At BMC, research is always in progress.

Learn more biomedcentral.com/submissions 